\title{
Frontal de altar y paneles cerámicos del siglo XVI en la Iglesia del Convento de Madre de Dios (Sevilla): estado de conservación y reconstrucción virtual
}

\author{
J.J. LUPION ALVAREZ*, M. ARJONILLA ALVAREZ**, A. RUIZ-CONDEx, P.J. SANCHEZ-SOTO \\ "Consorcio-Escuela de Formación de Artesanos de Gelves "Della Robbia", Consejería de Empleo, Junta de Andalucía, \\ Prado del Cañuelo s/n, 41120-Gelves (Sevilla) \\ **Departamento de Pintura, Facultad de Bellas Artes, Universidad de Sevilla \\ xInstituto de Ciencia de Materiales de Sevilla (ICMSE), Centro Mixto CSIC-US, c/Américo Vespucio $n^{\circ} 49$, \\ Centro de Investigaciones Científicas Isla de la Cartuja, Centro Mixto CSIC-US-Junta de Andalucía, Isla de la Cartuja, 41092-Sevilla
}

\begin{abstract}
Se describen y estudian una serie de composiciones cerámicas del Patrimonio Histórico-Artístico y Cultural (siglo XVI) que existen en la iglesia del Convento Madre de Dios de Sevilla. Se trata del denominado frontal de altar y dos paneles laterales, realizados mediante la técnica del azulejo plano polícromo $(12,5 \times 12,5 \mathrm{~cm})$. Son de temática apocalíptica y están ubicados debajo de un retablo de madera dedicado a San Juan Evangelista. El estudio llevado a cabo ha permitido apreciar su interés y singularidad desde el punto de vista histórico-artístico y ceramológico, con modelos poco frecuentes o desconocidos en la cerámica, en general, y sevillana en particular, así como su estado de conservación, que no es bueno debido a su notable deterioro.

Se discute sobre la documentación existente de la obra y las pruebas de su autoría por la firma AV.GTSA:FA que se atribuye a Cristóbal de Augusta, según se ha logrado deducir. Por último, se ha realizado una reconstrucción virtual de la obra mediante el uso de la fotografía digital y de herramientas informáticas, así como una propuesta de intervención para una posterior labor de restauración.
\end{abstract}

Palabras clave: azulejo, patrimonio cultural, frontal, zócalo, ceramología

'Frontal de altar' and ceramic panels (XVI century) into the church of Convento de Madre de Dios (Sevilla): conservation state and virtual re-construction

It is described and studied several ceramic compositions ( $16^{\text {th }}$ century) of Cultural Heritage, in the church of Convento Madre de Dios (Sevilla). It is dealed with the so-called "frontal de altar", and two ceramic panels at the side, made by the technic of polychrome plated tiles (size 12,5 $\times 12,5 \mathrm{~cm}$ ). This ceramic work is inspired in the Apocalipsis. They are located under an altarpiece in wood dedicated to St. John the Evangelist. The present study has allowed to evaluate highly its interest and singularity from both the historical-artistic and ceramology points of views, with models scarcely frequent or unknown in Ceramic Art, in general, and particularly at Sevilla. The conservation state of the ceramic composition in the frontal de altar was also investigated, being not so good due to their remarkable deterioration.

It is discussed the documentation that exists concerning this artistic work, and the proofs of the author by a signature (AV.GTSA:FA), which is attributed to Cristóbal de Augusta. Finally, it has been performed a virtual re-construction of the scene represented at the ceramic frontal de altar. For this purpose, digital photography and data treatment using computer methods have been applied. From all these results, it has been designed a proposal to take part in this artwork for a next possible restauration.

Keywords: ceramic tile, Cultural Heritage, face front of altar, socle, Ceramology

\section{INTRODUCCIÓN}

\subsection{El frontal de altar cerámico}

A lo largo de la historia de la cerámica la producción de objetos ha sido muy diversa, desde piezas con un marcado carácter utilitario hasta las que alcanzan un elevado nivel artístico $(1,2)$. Una producción que gozó de bastante aceptación por artistas de los siglos XVI y XVII fueron los frontales de cerámica o también frontales de azulejería para las mesas de altar. El frontal es la parte anterior del altar en una iglesia y que suele estar engalanado mediante paños decorados. Hace referencia a la frente y a su situación en la parte delantera. Consta de sobrefrontal, denominado también frontalera, el propio frontal del altar y las caídas. Se pueden destacar una serie de investigaciones donde se recogen gran número de ejemplares de este tipo de obra cerámica. Frothingam (3) hace un recorrido interesante y extenso en la cerámica española sobre este tema del frontal de altar cerámico. Por ejemplo, los de algunas poblaciones donde se ubican iglesias con frontales de altar de cerámica: Sevilla, Sanlúcar de Barrameda (Cádiz), Carmona (Sevilla), Córdoba, Calera de León (Badajoz), Talavera de la Reina, Maqueda, Lanzahita, Casar de Talavera, La Iglesuela, Plasencia, Toledo, Lima (Perú), etc. 
Con anterioridad a estas investigaciones, en una de las obras de Gestoso (4), este erudito autor menciona dos frontales de altar en la iglesia del convento Madre de Dios (Sevilla). El primero, a la izquierda de la puerta de entrada, está adornado con una ancha guardilla de motivos platerescos sobre fondo blanco. El motivo central es la figura de la Virgen con el Niño. Inmediato a éste hay otro frontal en un estado de conservación lamentable, con numerosas pérdidas y desorganización compositiva sobre temática del Apocalipsis de San Juan: en su origen, estuvo compuesto por 176 azulejos y es objeto de estudio en el presente trabajo. El mismo autor (4) ha descrito otro frontal de altar procedente del exconvento de religiosas de la Asunción. Desde 1868 esta obra está depositada en el Museo de Bellas Artes de Sevilla. Actualmente expuesto también en este Museo, existe un frontal dedicado a las Santas Justa y Rufina, coetáneo al de la iglesia de Santa María de Carmona (Sevilla) y algunos más, como por ejemplo las frontaleras (vide supra) de las dos capillitas dedicadas al Salvador y a Nuestra Señora de la Bendición, existentes en el Claustro del Monasterio de Santa Paula (Sevilla). En el Museo de Bellas Artes de Sevilla, en el Patio del Aljibe, se expone una mesa de altar atribuida al taller de la familia ceramista Pisano, realizado mediante casetones octogonales que copia un diseño descrito para artesonados (5). Es lástima que, con la larga tradición cerámica en Sevilla y su célebre barrio de Triana, con todos estos fondos tan notables y otros muchos, la propia ciudad de Sevilla siga sin poseer un verdadero Museo de Cerámica, a diferencia de otras ciudades españolas donde sí existen, como por ejemplo Valencia o Talavera de la Reina $(6,7)$, teniendo que exponer estas obras en dicho Museo de Bellas Artes.

Ahora bien, se plantea entonces la pregunta: ¿por qué se forraba de azulejos la mesa del altar? Se desconoce la idea inicial, pero el mismo Gestoso (4) entiende como favorecedor un auto del Cabildo Catedral de Sevilla, de principios del siglo XVII, disponiendo que se hiciesen para la Catedral unas frontaleras que pareciesen frontales. Lo que querían decir con esto es que se imitasen con azulejos los tejidos bordados que suelen utilizarse en los altares. Aunque frontalera es una parte del frontal de altar, a veces, y en distinta bibliografía, sirve como denominación de todo el frontal cerámico.

Conviene resaltar la importancia de este tipo de obras describiendo brevemente las de algunos autores conocidos. Es el caso del Oratorio de los Reyes Católicos en los Reales Alcázares de Sevilla (3), obra firmada por Niculoso "Il Pisano" en 1504 (NICULOSO FRANCISCO ITALIANO ME FECIT, 1504). Este ceramista italiano es una pieza clave para comprender la evolución de la cerámica sevillana, pues introduce el repertorio decorativo renacentista y una nueva técnica: el azulejo polícromo plano. Este frontal de altar está dedicado a la Anunciación y ha sido descrito por Gestoso (4). La innovación del Pisano tarda en adoptarse debido, entre otras causas, a la pujanza que en el siglo XVII tenía el azulejo de arista, o cuenca, y el de cuerda seca $(5,8)$. Siguiendo a Sancho Corbacho (9), en el palacio sevillano de los Duques de Medinaceli, conocido como Casa de Pilatos (10), se colocan azulejos de cuenca, pese al manifiesto deseo del Marqués de Tarifa de embellecerla "a la italiana". En la capilla de ese palacio, bajo una bóveda gótica de complicadas nervaduras, existe un frontal de altar muy interesante en el que los lenguajes cristiano y musulmán se unen al adoptar una decoración que imita al mosaico islámico de lacería de estrella de doce puntas. La técnica utilizada para la realización de los azulejos es la cuerda seca, procedimiento que en Sevilla tiene un importante desarrollo a partir del siglo XIII, llegando a su esplendor en el XVI. Asimismo, es necesario mencionar que la influencia italiana, traída a España probablemente por Niculoso Pisano y sus técnicas llegaron hasta la cerámica de Talavera. Y con ellas, la incorporación al repertorio iconográfico de la figura humana y la arquitectura (7). Como continuadores de la técnica del Pisano y tras un lapso de treinta años, se pueden mencionar varios ceramistas, algunos de ascendencia italiana (4). Uno de ellos es Juan de Valladares, iniciador de una notable saga. Destaca su hijo, Hernando, quien convierte el taller de su padre en el más importante de Triana desde 1595 a 1624. Así lo demuestra la cantidad de encargos que se le realizan para los Reales Alcázares de Sevilla, iglesia, coro y claustro del Monasterio de Santa Paula y otras muchas iglesias de Sevilla, exportando sus azulejos hasta Perú. Un frontal de altar, procedente del antiguo convento de la Asunción de Sevilla, ha sido atribuido a Hernando de Valladares y puede considerarse prototípico de los de su clase (11). Se trata de un frontal dedicado a las patronas de los ceramistas, las Santas mártires Justa y Rufina, alfareras de Triana. Está formado por 119 azulejos de 13 × $13 \mathrm{~cm}$. En su composición sigue la típica distribución de los frontales de tejido, estando incluso la frontalera separada de las caídas y el cuerpo por una cinta en naranja y verde, en recuerdo de los flecos que rematan la caída de un mantel. El diseño, a imitación de los bordados sobre un paño amarillo-dorado, está trazado mediante unas guarniciones de azul cobalto del que brotan elementos vegetales en distintos tonos de azul, verde y naranja. Este sinuoso motivo, varias veces repetido a distintas escalas, cubre por completo la superficie, con verdadero horror al vacío. También sirve de enlace, en la frontalera, de las cartelas que enmarcan los retratos de los santos patrones de Sevilla: San Isidoro, San Hermenegildo y San Leandro. Este frontal no pudo hacerse antes de 1598, ya que fue ese el año de la canonización de San Isidoro. Probablemente, Valladares lo diseñara muy cercano en el tiempo a otro que realizó para la iglesia de San Lorenzo y fechado en 1609, en el cual se representa un jarrón de azucenas como motivo central, símbolo de la pureza de la Virgen María. En relación a lo anteriormente expuesto, existe un grupo de frontales de altar distribuidos desde Sevilla a Sanlúcar de Barrameda (Cádiz) de similar decoración (3) que podrían ser atribuidos, sin duda, a Hernando de Valladares. Sin tener en cuenta las tiras cerámicas que los enmarcan, todos los frontales poseen 7 azulejos de alto y varían entre 17 a 19 azulejos de ancho.

Por último, en fecha más reciente, uno de los autores del presente trabajo (J.J.L.A.) ha tenido la suerte de poder apreciar en la capilla privada del antiguo palacio de los Condes de Ybarra, en Sevilla, que además del zócalo, allí existe un frontal de altar mucho más moderno que los anteriormente descritos. Se trata de una obra realizada por Gustavo Bacarisas (12), pintor nacido en Gibraltar y muerto en Sevilla, uno de los artistas más destacados de la primera mitad del siglo XX. Dicha obra responde a la genialidad de este artista y en un ejemplo que demuestra la calidad que pueden alcanzar algunas obras cerámicas.

\subsection{Objetivos del trabajo}

En este artículo se describen y estudian una serie de composiciones cerámicas que existen en la iglesia del Convento Madre de Dios de Sevilla, realizados en el último tercio del siglo 
XVI, como obras dentro del Patrimonio Histórico-Artístico y Cultural. Se trata de un frontal de altar y dos paneles laterales, realizados mediante la técnica del azulejo plano polícromo. El estudio realizado permite apreciar su interés y singularidad desde el punto de vista histórico-artístico y ceramológico, con modelos poco frecuentes o desconocidos en la cerámica, en general, y sevillana en particular. Un objetivo del trabajo de investigación ha sido tratar de identificar al autor de la obra principal, no mencionado categóricamente por ningún especialista hasta ahora. Asimismo, otros objetivos propuestos han sido establecer su estado de conservación, lo que ha dado lugar a una labor de organización del caos en el que se encontraban muchos azulejos para poder contemplar la escena representada, llevar a cabo una reconstrucción virtual de la obra, al menos como primera aproximación, y realizar una propuesta de intervención para una posterior labor de restauración.

\section{LAS COMPOSICIONES CERAMICAS EN LA IGLESIA DEL CONVENTO DE MADRE DE DIOS (SEVILLA)}

\subsection{Antecedentes históricos}

En el año de 1472 se fundó en Sevilla un beaterio para Religiosas Dominicas en un antiguo hospital situado junto a la denominada entonces Puerta de Triana, cerca de la actual calle Zaragoza. En una de las riadas del Guadalquivir, sucedida en 1485, este edificio quedó en un estado ruinoso y la comunidad recibió el auxilio de la Reina Isabel I la Católica que dona una manzana de casas confiscadas y situadas cerca de la parroquia de San Nicolás. A partir de 1551, las monjas deciden transformar este conjunto de casas en una residencia conventual e inician la construcción de la nueva iglesia del Convento de Madre de Dios. En 1572 el templo ya estaba concluido y se procedió a su ornamentación, prolongándose hasta 1598, fecha en la que ya se habían finalizado todas las pinturas, esculturas y retablos (13).

Al producirse la desamortización eclesiástica de 1868, en una parte del edificio conventual (claustro, refectorio y otras dependencias), se estableció la Escuela de Medicina, la cual permaneció transformada después en Facultad hasta 1931. A partir de este momento, la falta de vigilancia y el

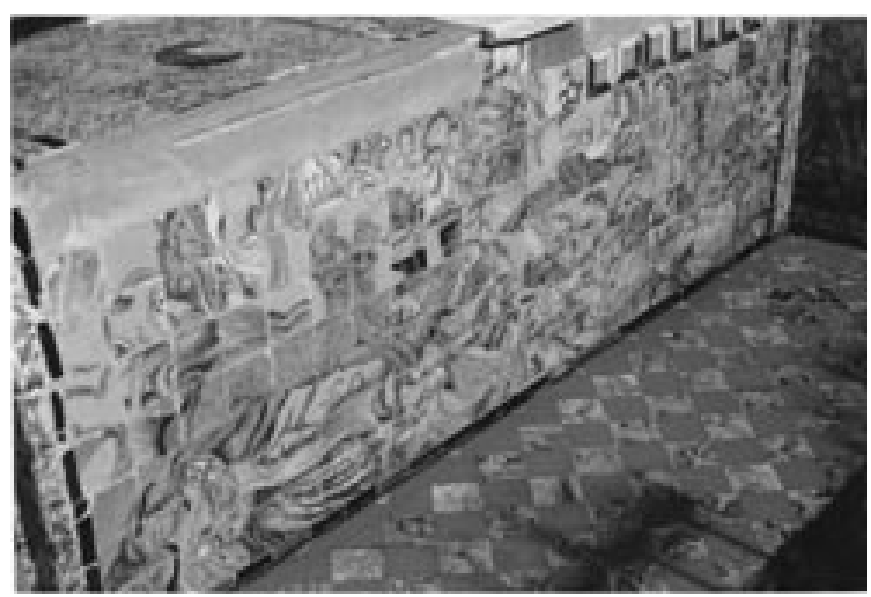

Fig. 1- Se muestra una perspectiva del estado del frontal de altar que se estudia en este trabajo y de parte de la solería más próxima a él, en la iglesia del convento Madre de Dios (Sevilla). expolio hizo desaparecer numerosos azulejos que cubrían el patio. Fue en 1934 cuando el Laboratorio de Arte de la Universidad de Sevilla consiguió que los restos de azulejos que aún se conservaban se trasladasen y colocasen en la misma Universidad, así como otros en el Museo de Bellas Artes de Sevilla (14). En la actualidad, en el convento de Madre de Dios, la azulejería plana polícroma y de arista está presente en distintas dependencias de la zona de clausura; también encontramos revestimientos de azulejería distribuidos por la única nave de la iglesia de dicho convento: en los muros, en zócalos, revistiendo capillas y mesas de altar, e incluso muchas piezas desperdigadas sirviendo de relleno en la solería de este templo (Figura 1).

\subsection{La técnica del azulejo plano polícromo a finales del siglo XVI}

Conviene resaltar que en la cerámica de la iglesia del convento de Madre de Dios de Sevilla se puede observar uno de los primeros testimonios, en Sevilla, del resurgir en el uso de una técnica cerámica introducida a finales del siglo XV o principios del XVI. Se trata de la técnica del azulejo plano polícromo, debida al ceramista Niculoso "il Pisano" ó Pisano. Se conocen como azulejos planos polícromos o azulejos pisanos. Tras la muerte de Pisano (¿1528?), se abrió un vacío de varios lustros en los que la técnica pisana no se utilizó en los alfares de Triana en Sevilla. Hasta hoy no se han encontrado obras que así lo atestigüen, como puede comprobarse en el palacio denominado Casa de Pilatos en Sevilla (4), cuyas primeras referencias de construcción se remontan a 1483 con la compra por Don Pedro Enríquez y su esposa, Catalina de Ribera, de una casa situada en la Parroquia de San Esteban (10). Este palacio fue decorado entre 1527 y 1536 con azulejos de cuenca, a pesar del gusto renacentista (a la italiana) del primer Marqués de Tarifa; o incluso el caso del cenador del Emperador Carlos V, en el Alcázar sevillano, que se decora también con azulejos de cuenca en 1545. La progresiva simplificación del proceso de fabricación del azulejo y la situación estratégica del puerto fluvial de Sevilla son algunas de las causas de su expansión comercial (8).

Será ya en el último tercio del siglo XVI cuando la técnica del azulejo plano polícromo comienza a resurgir con gran vigor para adornar palacios, edificios notables, templos, conventos, etc., utilizándose en zócalos, cuadros devocionales y también frontales de azulejería para las mesas de altar (siglos XVI y XVII), como ya se ha mencionado en la introducción.

\subsection{Descripción general de la obra cerámica de la iglesia del convento Madre de Dios}

2.3.1 Los revestimientos cerámicos pintados y zócalos. Olleros y azulejeros.

Esta obra cerámica que se estudia en el presente trabajo es muy interesante y singular desde el punto de vista históricoartístico y ceramológico ya que, incluso, se pueden encontrar modelos poco frecuentes o desconocidos en la cerámica española y sevillana, en particular. También permite apreciar el trabajo de tres generaciones emparentadas de ceramistas que poseían un taller en Sevilla.

Distribuidos por la única nave de la iglesia, pueden encontrarse revestimientos cerámicos pintados del ceramista Alonso García, de su yerno Roque Hernández ("ollero") y suegro, a su vez, de un azulejero llamado Cristóbal de 


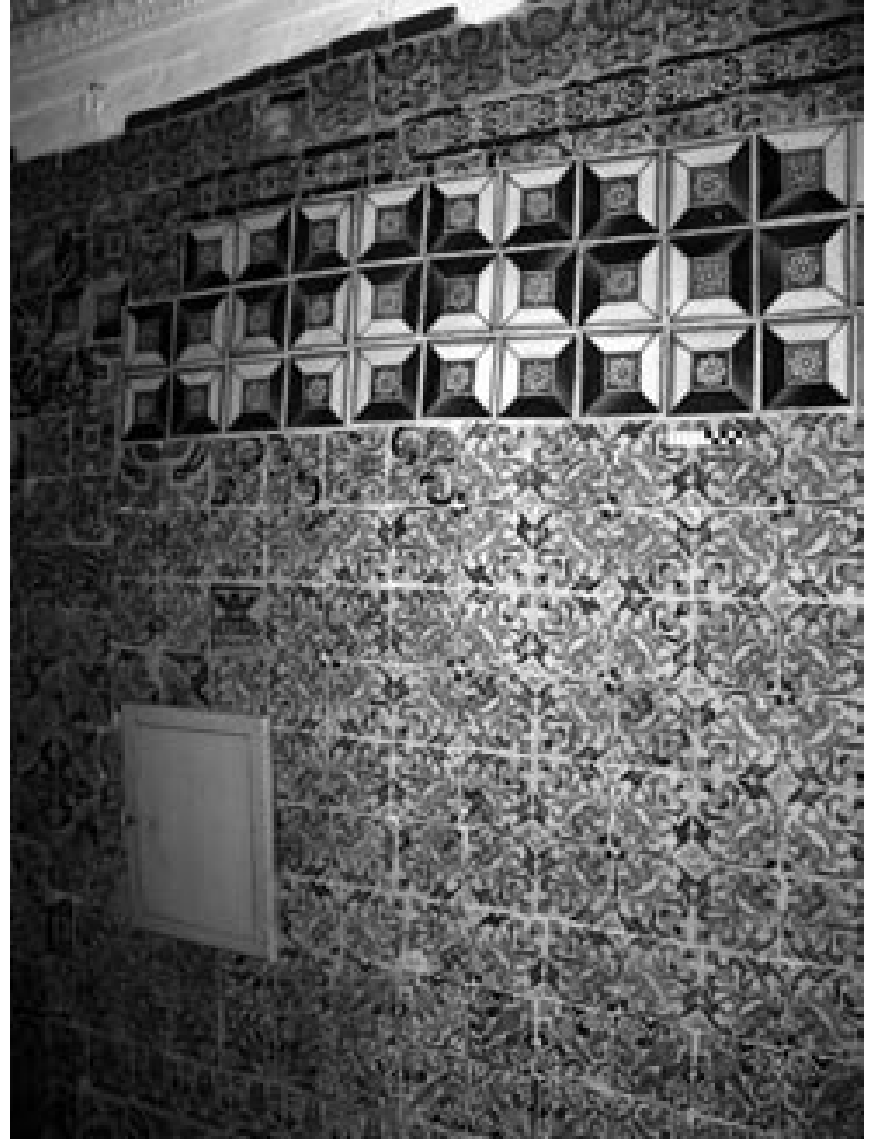

Fig. 2- Uno de los primeros ejemplos de cerámica polícroma plana posterior a Niculoso Pisano en Sevilla: zócalo de la Capilla del Correo de la iglesia del convento Madre de Dios, atribuida al Maestro Alonso García (1573).

Nota: Obsérvese en esta Figura la disposición de los azulejos en forma de estrella (con más detalle después en la Fig. 10) en relación a la distribución del mismo tipo de azulejos en el Peinador del Palacio de Velada, Talavera siglo XVI-XVII (estancia totalmente revestida de azulejería adquirida por el Museo de Cerámica de Talavera en 1972), como muestra la Fotografía de portada del Bol. Soc. Esp. Ceram V. 33 [6] 1994, autor Domingo Portela (Asociación Amigos del Museo de Cerámica "Ruiz de Luna". Talavera de la Reina).

Augusta. Es de interés mencionar que durante el siglo XVI, el término "ollero" fue habitual para denominar a todos los profesionales del barro y también existían otras específicas: tejeros, ladrilleros, botijeros, etc. Uno de los grupos más importantes pudo ser el de los "loceros", que hacían el menaje doméstico. La decoración arquitectónica, como azulejos o placas pintadas, la llevaban a cabo los "azulejeros" $(4,15)$. Los zócalos atribuidos a Alonso García, o Maestro Alonso (9), se fechan en 1573 y se considera uno de los ejemplos, de cierta importancia, que se realiza con la técnica del azulejo plano polícromo posterior a Niculoso Pisano. Se destaca el zócalo de la capilla del Correo en la misma iglesia del convento Madre de Dios (Figura 2).

En el lado de la epístola, a los pies del retablo de madera polícroma dedicado a San Juan Bautista, se encuentra un zócalo de azulejos de finales del siglo XVI, obra atribuida a Roque Hernández (13), ollero que sólo hacía azulejos esmaltados en la tradicional técnica de cuenca. A partir del año 1561, este ollero firmó un contrato con un pintor flamenco, Frans Andries (Francisco Andrea, ya como vecino en Triana), para que le enseñara "en el hazer de azulejos de piza y en el facer de loça de piza" (16). Esta última palabra se refiere, en efecto, a la ciudad de Pisa (Italia) como origen de ese tipo de "loça". Sería difícil asegurar si la obra es de Roque o de su yerno Cristóbal de Augusta, ya que pudieron colaborar juntos en el mismo taller. Un análisis pormenorizado de las obras de estos dos ceramistas podría aclarar algunas de estas atribuciones. Por otra parte, los paneles cerámicos del Apocalipsis merecen un estudio aparte.

\section{3. 2 Cerámicas del Altar del Apocalipsis}

En el lado opuesto del Evangelio, junto al presbiterio de la iglesia del convento de Madre de Dios, se haya un retablo dedicado a San Juan Evangelista, un conjunto escultórico en madera con escenas de la vida del Santo y del Apocalipsis (hacia 1575). La mesa del altar y los laterales están revestidos de azulejos planos polícromos de tamaño $12,5 \times 12,5 \mathrm{~cm}$. En los tres paneles se desarrollan escenas apocalípticas: “El Angel con la llave" (Figura 3), "Babilonia criminal" (Figura 4) y el frontal de altar de "Los Cuatro Jinetes del Apocalipsis" (Figuras 1 y 5). El frontal de altar es el que presenta peor estado de conservación, como después se describirá con más detalle en otro apartado.

\section{DISCUSION GENERAL SOBRE LA AUTORIA DE LA OBRA CERAMICA DEL ALTAR DEL APOCALIPSIS}

Para documentar esta obra, es imprescindible referirse a la investigación previa de Frothingham (3). Esta investigadora

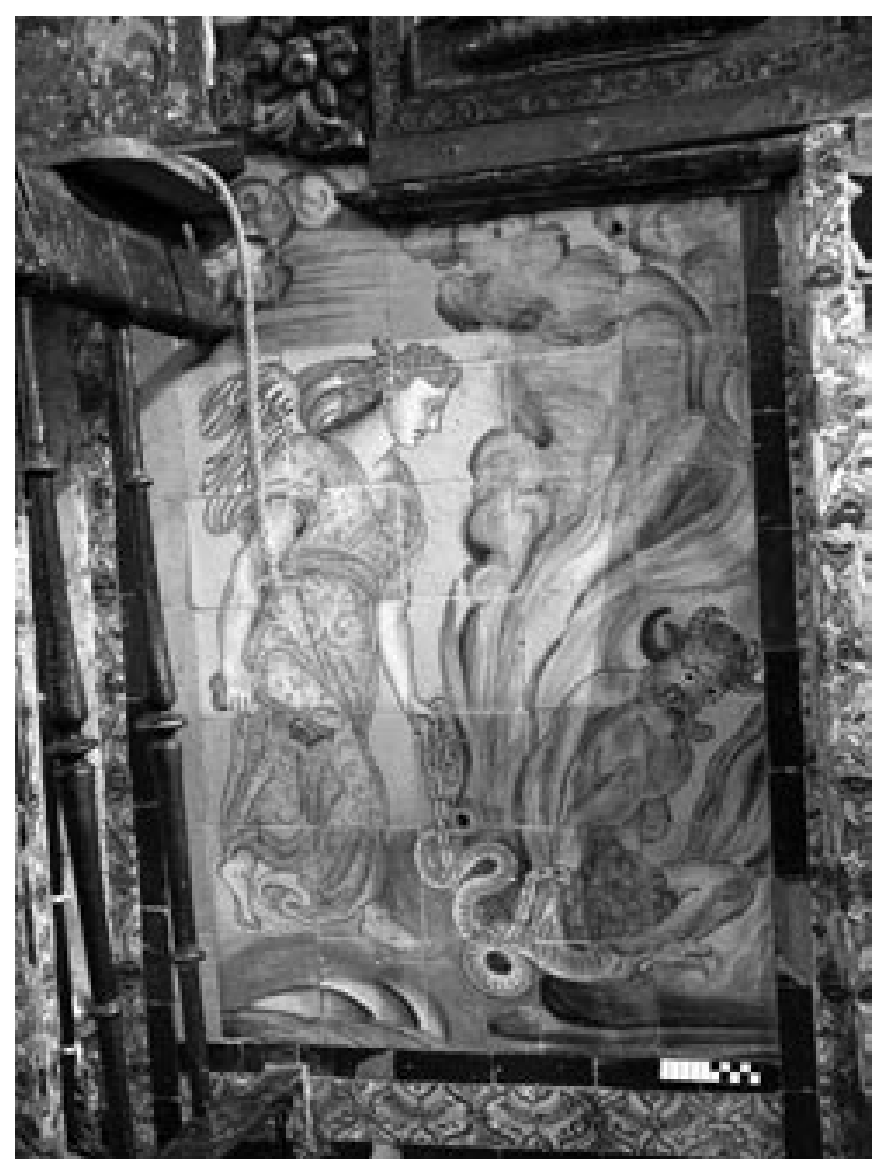

Fig. 3- Escena de "El Angel con la llave", junto al frontal de altar de la iglesia del convento Madre de Dios de Sevilla. 


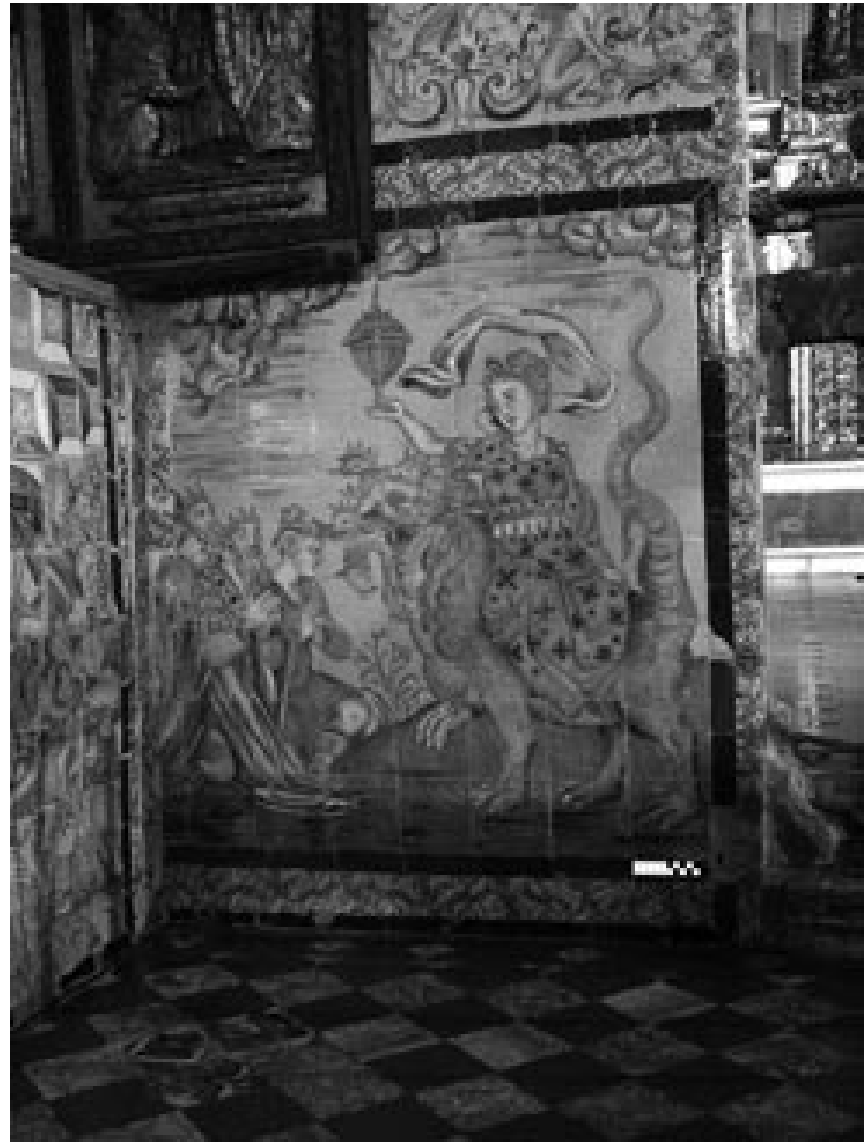

Fig. 4- Escena lateral de "Babilonia Criminal", junto al frontal de altar de la iglesia del convento Madre de Dios de Sevilla.

no encontró la firma del autor en los paneles cerámicos ("ninguno está firmado") y consideró que el contrato de esta obra pudo perderse en el incendio que destruyó el archivo del convento en 1598. No obstante, a pesar de no estar firmado, atribuyó el altar del Apocalipsis (Figura 6) al importante azulejero Cristóbal de Augusta (17).

Se debe puntualizar que uno de estos paneles cerámicos, en contra de lo expuesto por Frothingham (3), sí está firmado $\mathrm{o}$, al menos, posee una inscripción que se asocia a su autoría según la presente investigación. En concreto, se halla en el mismo frontal del altar: mediante minuciosa observación, se ha descubierto una inscripción en dos azulejos centrales, de la que hasta el momento no se tenía constancia de su existencia. En la Figura 6 se muestra en detalle y dice así: AV.GTSA:FA

La última sílaba de la inscripción está incompleta, ya que el azulejo posee un fragmento que se ha perdido (Fig. 6). Ante este hecho, la pregunta que sigue es ¿por qué ha pasado desapercibida esta firma a los distintos especialistas que han estudiado esta obra en diversas épocas?. Ni el erudito Gestoso (4), ni la pormenorizada investigación de Frothingham (3), ni la expresa publicación sobre los azulejos de Madre de Dios de Sancho Corbacho (14), entre las más destacadas investigaciones previas, han reparado en la firma de ese frontal de altar. Queda también preguntarse si, en efecto, es la firma de Cristóbal de Augusta. Si se responde afirmativamente, debe cuestionarse también ¿Por qué cambió el orden de las letras?

El deterioro sufrido, por el espacio que presenta (Fig. 6), permite añadir las letras "TI", quedando entonces "AV.

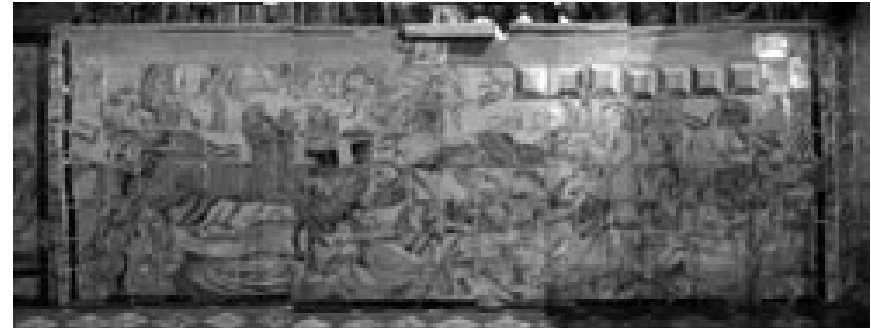

Fig. 5- Estado actual del frontal de altar dedicado a "Los Cuatro Jinetes del Apocalipsis" de la iglesia del convento Madre de Dios de Sevilla.

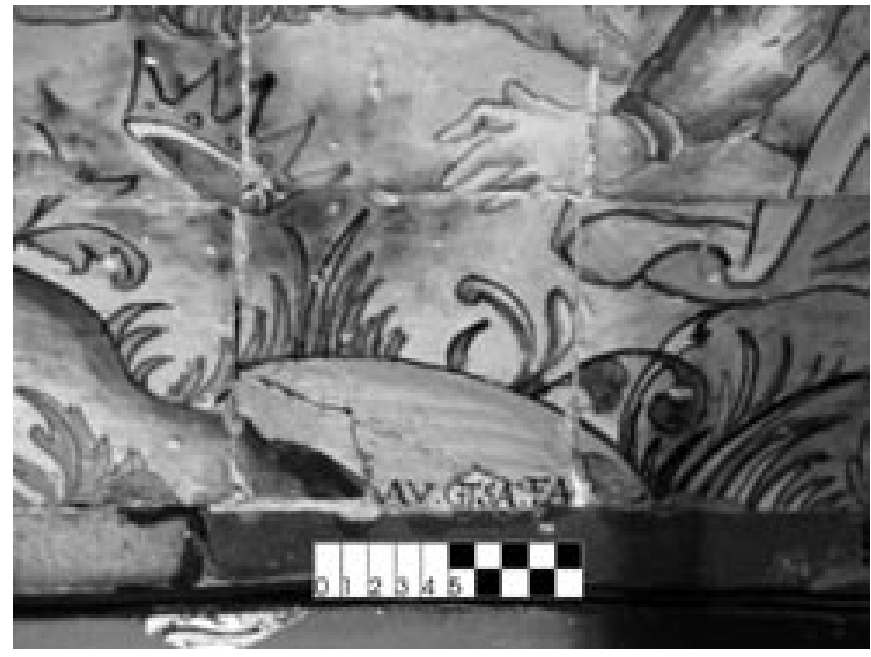

Fig. 6- Detalle de la inscripción en dos azulejos centrales del frontal de altar que, hasta esta investigación, ha pasado desapercibida a distintos especialistas que han estudiado esta obra cerámica en diversas épocas.

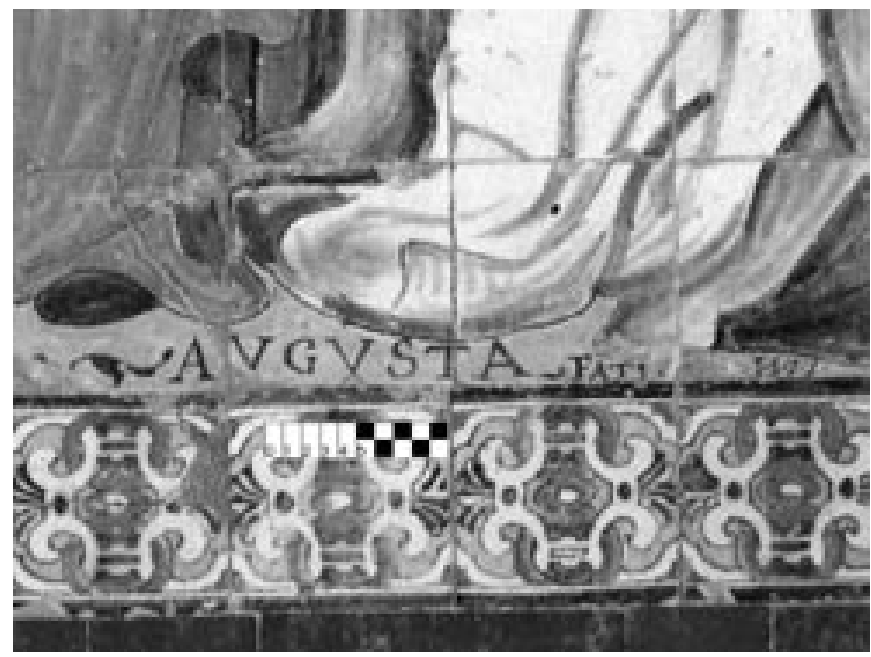

Fig. 7- Detalle de la inscripción con la firma del ceramista Cristóbal de Augusta que aparece en el panel cerámico de la Virgen del Rosario, fechado en 1577, realizado para el convento de Madre de Dios en donde estuvo hasta 1868. Obra actualmente en el Museo de Bellas Artes de Sevilla.

GTSA:FATI". Si esta fuese la reconstrucción acertada, ha de destacarse la notable semejanza con la firma que tiene el panel cerámico de la Virgen del Rosario, realizado en 1577, para el convento de la Madre de Dios, donde estuvo hasta 1868 y, en la actualidad, se encuentra en el Museo de Bellas Artes de 


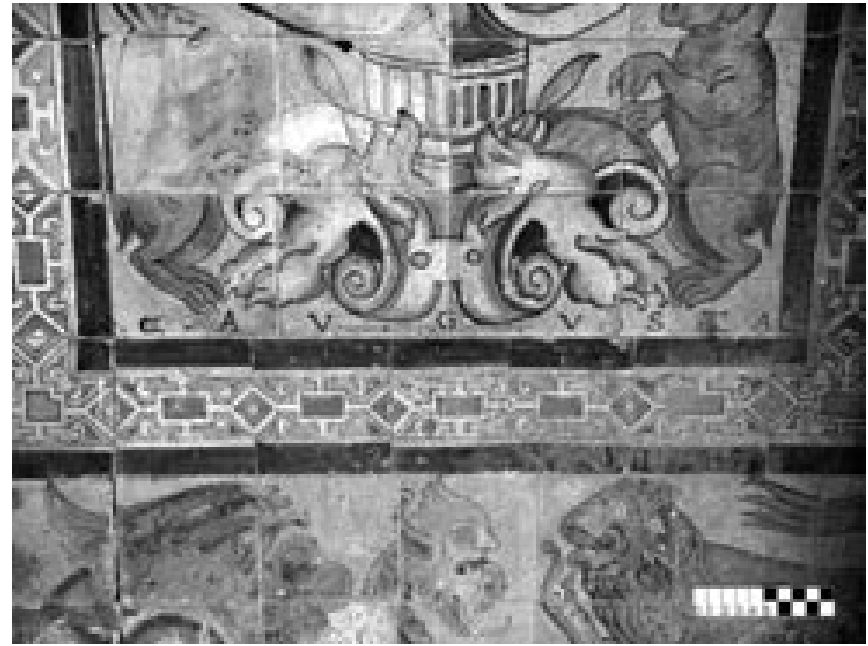

Fig. 8- Detalle del borde inferior de una estípite divisoria de los zócalos de los Reales Alcázares de Sevilla, donde aparece la inscripción AVGVSTA.

Sevilla, tal como se muestra en detalle en la Figura 7. En dicha obra aparece la firma "AV.GVSTA:FATI -1577" (Augusta Fati ¿ebat?). Existe un deterioro en esta obra (Fig. 7) que impide ver el final de la palabra "FATI ...", que podría ser "fatiebat".

Cristóbal de Augusta también es el autor de los zócalos de la "Sala de las Bóvedas o de las Fiestas", hoy conocidos como Salones de Carlos V, en los Reales Alcázares de Sevilla (4). En los plintos de las estípites divisorias de los tableros de dichos zócalos se puede leer la palabra "AVGVSTA", también "AVSTA" e incluso alguna otra variante como "AVGWWSTA" y fecha de 1578, como ilustran las Figuras 8 y 9.

Otra firma "AVGVSTA.PXC" además de una fecha MDLXX (está deteriorada, impidiendo ver la última cifra; por el espacio que queda, sólo puede ser una " $\mathrm{I}$ ", "V" ó bien " $X$ ", por lo que se fecha en 1570-1580), aparece en un cuadro incompleto titulado "Resurrección del Señor" (en la actualidad se encuentra esta obra en el Instituto Valencia de Don Juan). En fecha reciente (18), ha aparecido una placa con la figura de San Roque, fechada en 1582 según parece apreciarse, también firmada por AVGVSTA.

Todo lo anteriormente expuesto hace pensar que Cristóbal

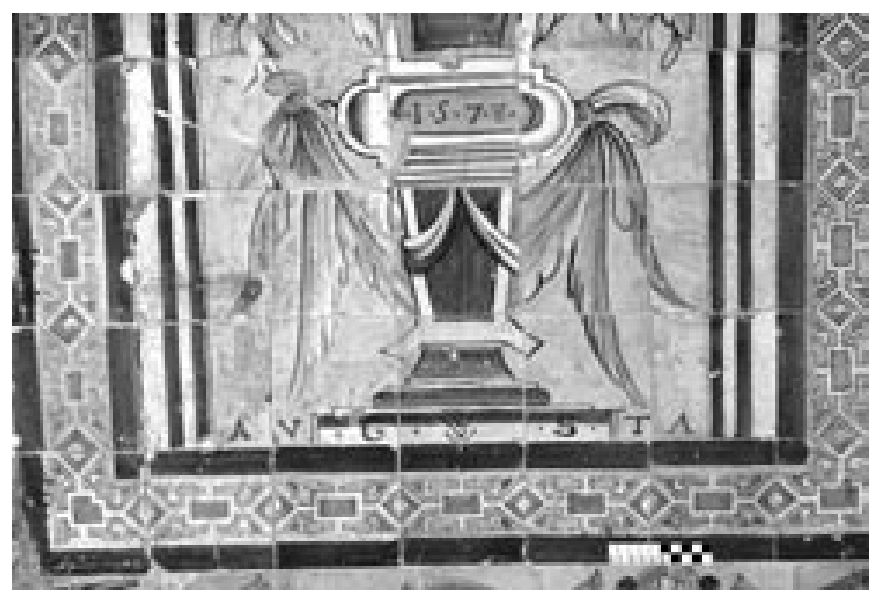

Fig. 9- Detalle del borde inferior de otra estípite divisoria de los zócalos de los Reales Alcázares de Sevilla, donde aparece la fecha de su realización (1578) y otra variante de la inscripción mostrada en la Fig. 8. de Augusta no siempre utilizaba un único modo de firmar sus obras, como ha podido comprobarse. Pero respecto al panel de la iglesia del convento Madre de Dios, objeto del presente estudio, también cabe preguntarse: ¿Por qué cambió el orden de las letras? A partir de un examen de los papeles del ignorado archivo del Alcázar de Sevilla, Gestoso (4) ofrece bastante información sobre Augusta: pintor de azulejo de la obra de Italia, hijo legítimo de Cristóbal de Augusta y de Isabel de Dicastillo, su mujer, vecinos que fueron de la ciudad de Estella ("que es en el reyno de navarra"). Este autor publica incluso su contrato con el Alcázar para hacer los azulejos de la "Sala de las Fiestas", ya mencionada, tras haber enseñado un boceto y una muestra. La magnitud de esta obra es tal que el conjunto de zócalos del vestíbulo, salones y capilla suman una superficie de 589.07 metros cuadrados. Una condición impuesta a Augusta por escrito es la de hacer todos los azulejos sin llevar a cabo otros trabajos mientras durase el del Alcázar, es decir, una especie de contrato de exclusividad que se transcribe a continuación:

"sin ocuparse ni labrar en su casa ni fuera della obra ninguna todo el tiempo que durase la obra de los dichos azulejos para los dichos alcaçares".

El contrato tiene fecha de "ochodias del mes de março de mill e quinientos e setenta e siete años". Y de todo lo anterior se puede deducir una interpretación sobre la inscripción descubierta (Fig. 6).

Una hipótesis podría ser que Augusta terminase su Virgen del Rosario antes de marzo de 1577. Por tanto, pudo fechar y firmar su obra, como tenía costumbre. Una siguiente hipótesis sería que el Altar del Apocalipsis era otro encargo del Convento, posterior a marzo de 1577, cuando ya trabajaba en la obra del Alcázar de Sevilla y no podía hacer "obra ninguna". Por consiguiente, esto le condicionó a no fechar y a disimular su nombre usando, por ejemplo, algo similar a un seudónimo para ser discretamente conocido (Fig. 6).

\section{ESTADO DE CONSERVACION}

Dentro de las obras cerámicas de interés artístico de la iglesia del convento Madre de Dios de Sevilla, el frontal de altar es el que presenta peor estado de conservación, ya que es imposible visualizar la escena que se reproduce debido a que los azulejos, en su mayor parte, están fuera de su posición original como se observa en la Figura 5. Se conoce que el deterioro ya estaba presente a principios del siglo $\mathrm{XX}$, cuando Gestoso (4) menciona que el estado de conservación de esta obra ya era lamentable, con muchos azulejos desprendidos y, además, debido a que estaba "oculta por un forro de madera, ignorábase su existencia". Este autor también menciona que los azulejos desprendidos se habían utilizado, de una forma que califica de torpe, para reparar (o más bien, remendar) la solería, como se observa en la Figura 1 en la parte que aparece de dicha solería. Incluso varios de los azulejos, y partes de ellos, están actualmente repartidos por diferentes muros de la nave de la iglesia.

El estado de conservación del frontal de altar puede calificarse en la actualidad de pésimo (Fig. 5). La problemática que presenta se debe, sobre todo, a la inestabilidad que posee la obra en el inmueble donde se ubica. El deterioro principal se basa en una disminución del agarre de los morteros empleados, lo que ha ocasionado separaciones (abofamientos) entre la pared y los azulejos del conjunto y el desprendimiento continuo, durante muchos años, de 


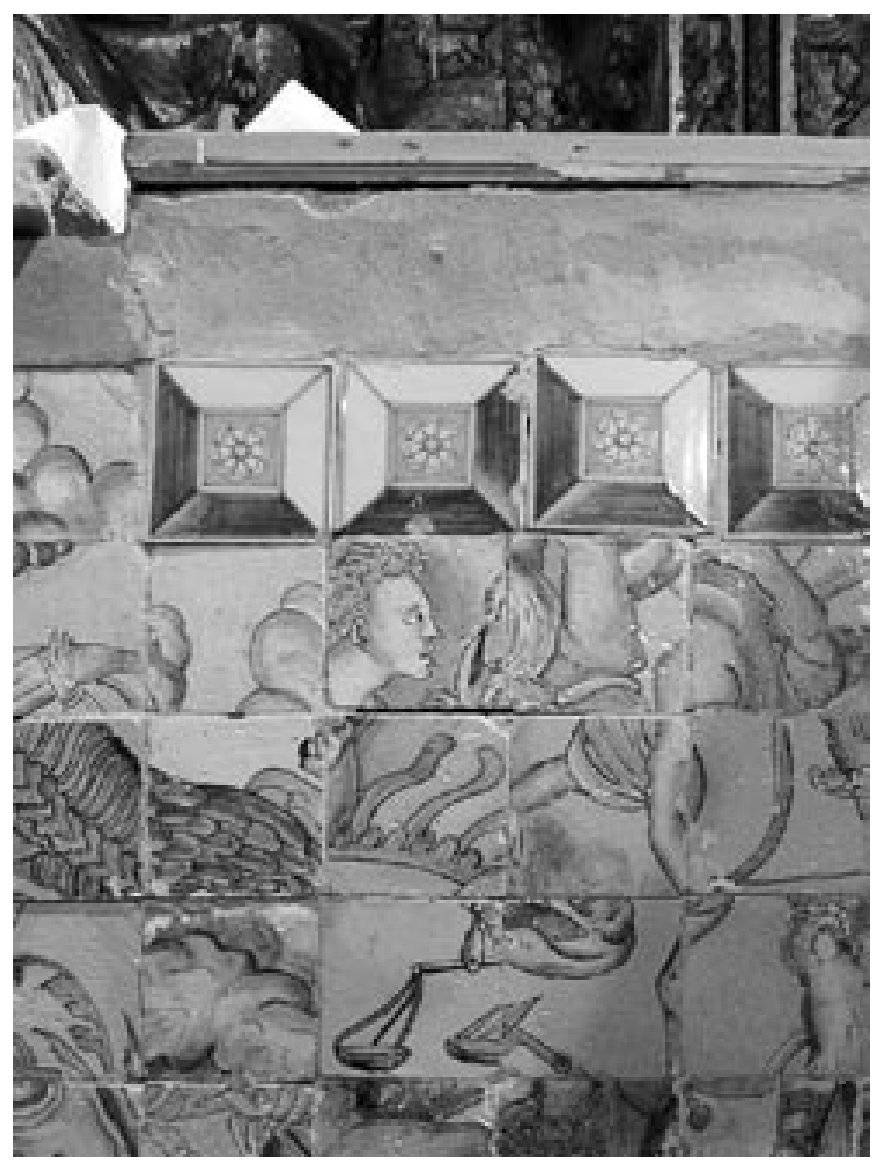

Fig. 10- Detalle ilustrativo del deterioro actual que presenta el frontal de altar dedicado a "Los Cuatro Jinetes del Apocalipsis" de la iglesia del convento Madre de Dios de Sevilla, con pérdidas del original e imposibilidad de visualizar y entender la escena representada debido a que los azulejos, en su mayor parte, están fuera de su posición original (véase el texto).

multitud de ellos. Ello ha provocado las pérdidas o roturas de las piezas y el desorden de los mismos, con deterioro a nivel estético. A título ilustrativo, se muestran varios detalles de los daños y deterioros en las Figuras 10 y 11. La degradación que ha sufrido esta obra ha sido constante durante los últimos cien años por haberse intervenido, además, con reparaciones parciales. Dichas reparaciones parciales no han buscado la eliminación de las causas de la degradación, sino que se han limitado a reponer piezas sueltas, así como a rellenar con mortero y otros elementos extraños las pérdidas de material. Esta falta de adhesión entre la pared del muro y los azulejos puede ser debida a distintos factores, como es una mala puesta en obra, además de una aportación de sales que trae consigo la humedad del suelo. Incluso podría deberse al envejecimiento de los morteros que provocaron una pérdida de su resistencia mecánica. De hecho, la humedad ha afectado a la obra con pérdida de cromatismo en los colores de las figuras y formación de halos blanquecinos, con origen en la migración de sales disueltas. El muro donde se encuentra también está afectado por agujeros, golpes y rozaduras, además de una capa de suciedad y pérdida de mortero.

Un estudio más detallado de la obra y del inmueble, que está todavía por realizar, con distintas tomas de muestras y los análisis correspondientes, determinará más certeramente

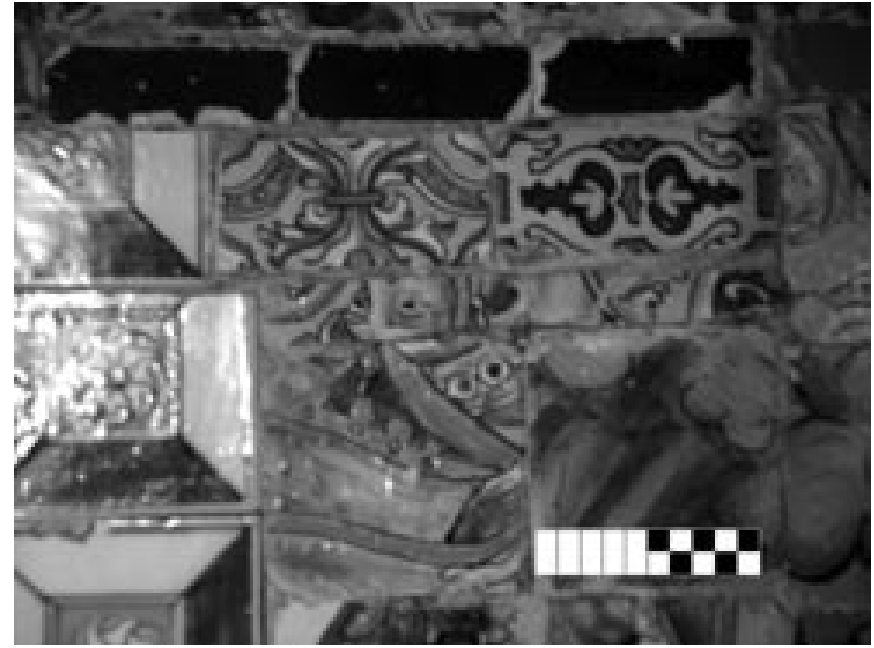

Fig. 11- Otro detalle ilustrativo del deterioro del frontal de altar con disminución del agarre de los morteros que ha ocasionado abofamientos del conjunto y desprendimientos continuos, durante muchos años de los azulejos, provocando su desorden y las pérdidas o roturas de las piezas.

las causas principales de la alteración y permitirá, en suma, proponer el tratamiento más adecuado para una urgentísima intervención.

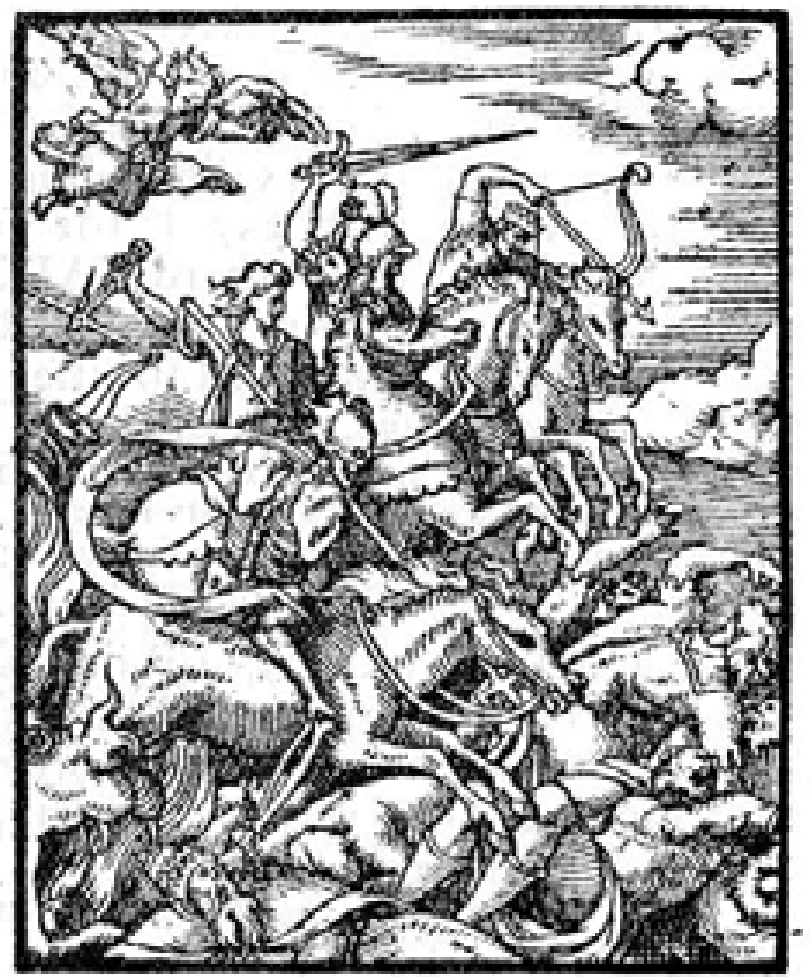

Fig. 12- Reproducción del grabado con la escena de los Cuatro Jinetes del Apocalipsis en la que, según Frothingham (3), se basó el autor del frontal del altar. Ilustraciones del Apocalipsis atribuidas a Bernard Salomón, publicadas en un volumen titulado "Figures du Nouveau Testament", en la ciudad de Lyon (Francia), año de 1554. 


\section{DOCUMENTACION PARA UNA RECONSTRUCCION VIRTUAL Y RESULTADO}

El interés de la publicación de Frothingham (3) que ya se ha comentado, viene también señalado para el presente estudio debido a que expone las fuentes de inspiración del Altar del Apocalipsis y, en particular, para el frontal del altar. Se trata de escenas idénticas que se publicaron en el año 1554 en Lyon (Francia), en un volumen titulado "Figures du Nouveau Testament". Las ilustraciones del Apocalipsis, atribuidas a Bernard Salomón, incluyen a Los Cuatro Jinetes, Babilonia criminal y el Angel con la Llave que también aparecen en la iglesia del convento de Madre de Dios de Sevilla (Figs. 3-5).

Una vez localizado así el grabado de los Cuatro Jinetes del Apocalipsis (Figura 12), en el cual se basó Cristóbal de Augusta, aunque no aparezca en la publicación de Frothingham (3), se puede comprobar el parecido de la escena y la semejanza de las figuras principales (Fig. 5). Sin embargo, se comprueba que su distribución por la escena es más separada en el frontal del altar de esta iglesia. En este caso particular, al contar con las fuentes gráficas en las que se inspiró el autor de esta obra, se facilita la realización de una reconstrucción informática o reconstrucción virtual de la misma en su apariencia lo más próxima al original.

Mediante el uso de la fotografía digital y el empleo de herramientas informáticas para un retoque fotográfico, se ha realizado una reconstrucción virtual de esta escena del Apocalipsis (Figs. 12 y 5) como primera aproximación. El equipo utilizado está compuesto por una cámara digital Pentax Optio 555 de 5,0 megapixels y un ordenador personal Intel Pentium III de 1.0B GHz, 256 RAM e impresora a color, utilizando un programa de retoque fotográfico, que en el caso presente ha sido el Corel Photo-Paint 111. Para reconstruir virtualmente la escena, se procedió a realizar un amplio reportaje del altar mediante fotografía digital de sus elementos. Estos se descargaron en una cuadrícula diseñada previamente, ordenándose, girando o moviendo, mediante las funciones "cortar y pegar" del programa de retoque digital.

Después se inició otra sesión fotográfica de todos los azulejos completos o fragmentos que, repartidos por otros zócalos de la iglesia, pudieran emparentarse con los originales. De igual forma, se descargaron sobre la cuadrícula y se fue comprobando su encaje.

El resultado obtenido se presenta en la Figura 13 y se puede comparar con el original a escala semejante, mostrado en la Figura 5. El objeto de llevarlo a cabo ha sido de servir de

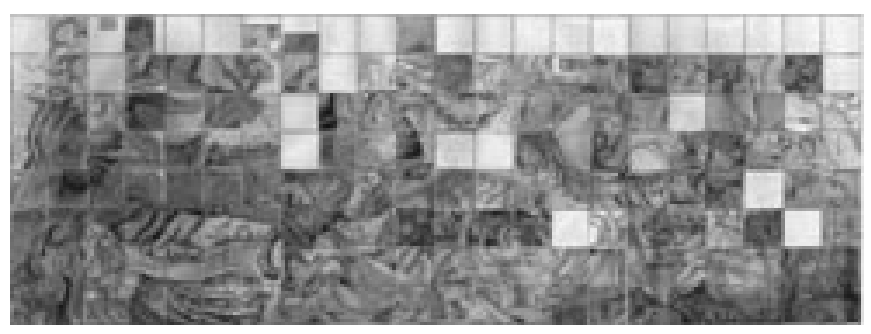

Fig. 13- Resultado de una reconstrucción virtual mediante fotografía digital y herramientas informáticas de la escena del frontal de altar donde se aprecian los Cuatro Jinetes del Apocalipsis. Están incluidos todos los azulejos hasta ahora localizados por los zócalos de la iglesia. Compárese el resultado con el frontal de altar original tal como se muestra en la Fig. 1 y, a escala similar, en la Fig. 5. documentación, en una primera aproximación como ya se ha indicado, al estudio e investigación de la obra y para poder visualizar el conjunto sin intervenir directamente sobre la misma obra. Es evidente la ventaja que se obtiene así sobre las investigaciones previas ya mencionadas $(3,4,14)$, dado que no se disponía de estas técnicas, siendo un primer paso para su diagnóstico antes de la restauración y conservación.

Además, el resultado de esta reconstrucción virtual ha servido para poder comprobar el encaje de los distintos azulejos planos polícromos de la obra que están dispersos por los muros del propio templo. Hasta ahora no se han podido localizar veintiocho azulejos completos y algunos fragmentos, pero el proceso realizado facilita visualizar la imagen del original. Se puede anticipar que el proyecto de intervención no puede actuar sólo en el frontal, sino en muros perimetrales donde existen azulejos que pertenecen al altar.

\section{SUMARIO, CONCLUSIONES Y PROPUESTA DE INTERVENCION}

En la iglesia del convento de Madre de Dios de Sevilla, debajo del retablo de madera dedicado a San Juan Bautista, existen tres paneles cerámicos que recubren la mesa del altar y los laterales con escenas del Apocalipsis. Este conjunto se ha realizado con azulejos planos polícromos pintados, una técnica que resurge en Sevilla en el último tercio del siglo XVI, en clara competencia con el acostumbrado uso del azulejo de cuenca.

Mediante un minucioso estudio directo de la obra del frontal del altar, en dos de los azulejos se ha encontrado una inscripción que se ha considerado una posible firma del autor de la obra. Hasta este momento, dicha inscripción no se había mencionado por ningún especialista que la haya investigado $(3,4)$. Aparece como AV.GTSA:FA y sin fechar en la composición. Mediante una investigación documental sobre otras obras cerámicas firmadas y fechadas, se deduce y concluye que dicha firma se identifica perteneciente al ceramista Cristóbal de Augusta, el cual, por circunstancias de exclusividad en otro trabajo, tuvo que dejar constancia así de su autoría. Se trata de un importante ceramista del siglo XVI afincado en Sevilla y autor, entre otras obras destacadas, de la Virgen del Rosario (realizada en 1577) para este mismo convento y que se expone en el Museo de Bellas Artes de Sevilla. Destaca también, por su magnitud y características, otra obra muy conocida de Augusta que son los azulejos que revisten los Salones de Carlos V en los Reales Alcázares de Sevilla.

El estado de conservación de este conjunto no es bueno y puede calificarse de pésimo. El frontal de altar presenta una situación lamentable, con muchas pérdidas, sustituciones y añadidos de piezas y reparaciones con mortero, además del efecto pernicioso de la humedad con migración de sales. Otro deterioro importante se establece a nivel estético por sus muchos azulejos desorganizados que hacen imposible no ya entender, ni siquiera vislumbrar la escena que se reproduce a menos que se conozca que representa alguna propia del Apocalipsis por su proximidad a un retablo con San Juan Bautista. Esta desorganización impide, además, conocer el número de piezas originales que aún se mantienen. Por tanto, como una primera aproximación para intervenir en la obra, se ha recurrido a fuentes documentales (grabado de escenas del Apocalipsis), fotografía digital y aplicación de herramientas informáticas para poder establecer, al menos 
con una reconstrucción virtual, cuántos azulejos permanecen en la obra original del artista y cuántos son ajenos o se han perdido, además de poder conseguir comprender en sí cómo es la escena que se representa.

Se pretendía organizar el caos en el que se encontraban muchos azulejos para poder contemplar la escena representada y poder establecer su estado de conservación. También el proceso llevado a cabo ha permitido conocer el número de azulejos que faltan o bien los que han sido añadidos y no pertenecen al panel. Además, dicho proceso ha facilitado realizar un encaje de otros azulejos repartidos por los muros de la iglesia. Esto es importante a la hora de comprobar su pertenencia al altar cerámico, ya que al proyectar una intervención sobre el altar, debe tenerse en cuenta la actuación y arranque de azulejos en otras paredes de la misma. De este modo, tras comprobar el número de piezas que faltan, se ha procedido a inspeccionar los zócalos del edificio. Se han encontrado azulejos que ofrecían un parecido con los originales del frontal del altar. Mediante la fotografía digital y con el uso de un programa informático de retoque fotográfico, se ha conseguido llevar a cabo una reconstrucción informática o virtual de la obra, tal como se expone en este trabajo. Ello ha permitido comprobar el encaje, en los faltantes de la obra, de los azulejos repartidos por los diferentes zócalos de la iglesia del convento madre de Dios de Sevilla.

En consecuencia, se ha podido prever que, además del frontal del altar, una propuesta de intervención para su restauración debería llevar asociada otra en los muros de la iglesia, ya que sería necesario realizar una extracción de azulejos originales. Como fase inicial de la restauración, además de una limpieza superficial con agentes no agresivos, se debe aplicar un tratamiento preventivo de urgencia que frene el avance del deterioro y pérdidas de trozos de azulejos de la obra. Si no se procede así, se produciría en un próximo futuro una casi imposible recuperación de zonas vitales de esta artística composición sobre el Apocalipsis, obra que se ha demostrado realizada por Cristóbal de Augusta en el siglo XVI.

\section{AGRADECIMIENTOS}

Se agradece el apoyo recibido por la Consejería de Empleo de la Junta de Andalucía y el Ayuntamiento de Gelves al Consorcio-Escuela de Formación "Della Robbia". Este agradecimiento se hace extensivo al Departamento de Pintura de la Facultad de Bellas Artes de Sevilla por su colaboración. Asimismo, se agradece la financiación recibida al Proyecto de investigación MAT2002-02549, mencionando que está cofinanciado en parte con Feder, en el marco del cual se ha realizado este trabajo, así como a la Junta de Andalucía, Grupo TEP204 (III Plan Andaluz de Investigación) que ha facilitado el inicio de estas investigaciones.

\section{BIBLIOGRAFÍA}

1. F. Singer, S.S. Singer, Cerámica Industrial, Vols. 1-3, Enciclopedia de la Química Industrial, Tomos 9-11, Editorial Urmo, Barcelona, 1971.

2. F. Cottier-Angeli, La Cerámica, $2^{a}$ reimpresión (1980) de la obra original "La Cerámique" en versión castellana de Janine Muls de Liarás, ediciones Rufino Torres, Barcelona, 1974. 172 pp.

3. A.W. Frothingham, Tile panels of Spain: 1500-1650, New York, 1969. 106 pp.

4. J. Gestoso y Pérez, Historia de los barros vidriados sevillanos desde sus orígenes hasta nuestros días, Sevilla, 1904. 459 pp. En particular, págs. 166-253. Se trata de la edición de la Colección clásicos sevillanos número 8, Servicio de Publicaciones y Distrito Triana, Excmo. Ayuntamiento de Sevilla, 1995.

5. A.J. Morales Martínez, Francisco Niculoso Pisano, Excma. Diputación Provincial de Sevilla, 1977. 130 pp.

6. J. Coll Conesa, Museo Nacional de Cerámica y de las Artes Suntuarias "González Martí", Bol. Soc. Esp. Ceram. V. 33 [6] 337-339 (1994). Nota: Véase también la Fotografía de portada de Bol. Soc. Esp. Ceram.. V. 33 [6] 1994 (autor: Domingo Portela, Asociación Amigos del Museo de Cerámica "Ruiz de Luna", Talavera de la Reina).

7. VV.AA., El nuevo museo de cerámica de Talavera, Bol. Soc. Esp. Ceram. V. 33 [6] 341-344 (1994)

8. A. Pleguezuelo Hernández, Azulejo sevillano, Ed. Padilla, Sevilla, 1989. 171 pp.

9. A. Sancho Corbacho, La cerámica andaluza. Azulejos sevillanos del siglo XVI, Universidad de Sevilla, 1948. $61 \mathrm{pp}$

10. V. Lleó Cañal, La Casa de Pilatos, Edita Caja San Fernando, Sevilla, 1996. 213 pp.

11. VV.AA., Museo de Bellas Artes de Sevilla, Editorial Galve, Sevilla, 1993. $412 \mathrm{pp}$.

12. J.J. Lupión Alvarez, El frontal de altar cerámico, Cuadernos de Restauración 4, 93-98 (2002).

13. E. Valdivieso González, Morales Martínez A.J., Sevilla oculta. Monasterios y Conventos de Clausura, Ed. Guadalquivir, Sevilla, 1991. 299 pp.

14. A. Sáncho Corbacho, Los azulejos de Madre de Dios de Sevilla, Archivo Español de Arte, XII, 215-224 (1949).

15. J.M. Sánchez Cortegana, El oficio de ollero en Sevilla en el siglo XVI, Edita Excma. Diputación de Sevilla, 1994. 165 pp.

16. En ref. 4, pág. 223.

17. En ref. 3, transcribiendo a continuación lo más importante sobre esta obra y su autoría: “Dentro de lo que ahora es la iglesia de la parroquia de Madre de Dios, antes la capilla del convento, se encuentra un altar lateral dedicado a San Juan Evangelista, con su retablo tallado en madera que ilustra escenas del Apocalipsis. Tres paneles de azulejo cubren el frontal del altar y las paredes inmediatas, ninguno de ellos está firmado y todos están pintados con escenas apocalípticas complementarias al retablo. El frontal, originariamente de 176 azulejos, representa a los Cuatro Jinetes (...) y está en pésimas condiciones, muchos de los azulejos se han perdido o cambiado de sitio. Si el cuadro fuese reconstruido, se podría ver a la izquierda el esqueleto de la Peste sobre un caballo pardo saliendo de la boca del Infierno (...) Luego viene el Hambre, con una balanza en su mano (...) Incluso sin la prueba innegable de un contrato o una anotación, parece que los paneles de Madre de Dios deben atribuirse a Cristóbal de Augusta".

18. A. Pleguezuelo Hernández, Cerámica de Sevilla (1248-1841), Summa Artis, Vol. XLII, 343-386 (1992)

Recibido: 23.12.05

Aceptado: 29.03.06 